\title{
Cold Compaction of Ball-Milled Nanograin Iron Alloys
}

\author{
A. Munitz and Z. Livne \\ Nuclear Research Center Negev \\ Beer-Sheva, Israel \\ J. C. Rawers \\ U.S. Dept. of Energy \\ Albany, OR 97321 \\ R. J. Fields \\ Metallurgy Division \\ NIST \\ Gaithersburg, MD 20899
}

QC

100

.056

NLT

N0.5991 


\section{NISTIR 5991}

\section{Cold Compaction of Ball-Milled Nanogirain Iron Alloys}

\section{A. Munitz and Z. Livne}

Nuclear Research Center Negev

Beer-Sheva, Israel

\section{J. C. Rawers}

U.S. Dept. of Energy

Albany, OR 97321

\section{R. J. Fields}

Metallurgy Division

NIST

Gaithersburg, MD 20899

March 13, 1997

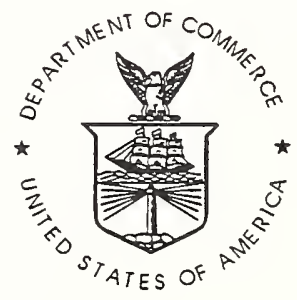

U.S. DEPARTMENT OF COMMERCE

William M. Daley, Secretary

TECHNOLOGY ADMINISTRATION

Gary Bachula, Acting Under Secretary for Technology

NATIONAL INSTITUTE OF STANDARDS

AND TECHNOLOGY

Robert E. Hebner, Acting Director 


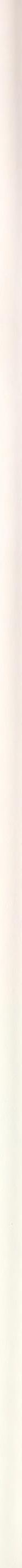




\section{COLD COMPACTION OF BALL-MILLED NANOGRAIN}

\section{IRON ALLOYS}

A. Munitz ${ }^{a}$, Z. Livne $e^{a}$, J. C. Rawers ${ }^{b}$ and R. J. Fields

National Institute of Standards and Technology, Gaithersburg, MD 20899

${ }^{a}$ Nuclear Research Center Negev; Beer-Sheva, Israel

${ }^{b}$ U.S. Bureau of Mines Albany, Oregon 97321

\section{ABSTRACT}

A cold dynamic consolidation-CDC technique is presented that can produce high density, high hardness compacts from ball-milled nanograined powders. The resulting compacts were characterized using optical and scanning electron microscopy, microhardness, and density measurements. For comparison, the powders were initially either compacted using $0.35 \mathrm{GPa}$ CIP or compacted in a die up to $2.5 \mathrm{GPa}$. The CIPed compacts of ball-milled powders had a low relative density, (approximately 60\%), low hardness, (100 $\mathrm{H}_{\mathrm{V}}$-Vickers hardness), and no indication of interparticle bonding. Increasing the compaction pressure to $2.5 \mathrm{GPa}$ increased the density to about $72 \%$, but did not improve bonding. In contrast, the CDC technique produced compacts which had densities approaching $95 \%$ of the theoretical values. In some cases, the hardness of ball-milled powder compacts exceeded $1400 \mathrm{H}_{\mathrm{V}}$, and the microstructure showed that intimate contact had been achieved during the dynamic compaction. It is believed that high density bodies will enhance bonding during sintering at lower temperature, thus minimizing the average grain size and maximizing the mechanical properties. 


\section{1) INTRODUCTION}

Recently there has been an increasing interest in nanocrystalline materials due to novel properties which they possess. A nanocrystalline metal powder has grain sizes ranging between $5 \mathrm{~nm}$ and $100 \mathrm{~nm}$. At such small grain sizes the number of atoms located at the grain-boundaries is relatively large compared to the number of atoms located within the grains ${ }^{(1)}$. This could strongly influence the magnetic, optical, and/or mechanical properties if one succeeded in consolidating the powder to a compact body while preserving the nanoscale grain size.

There are various ways to synthesize nanocrystalline powders, such as evaporation/condensation ${ }^{(2-3)}$, sol-gel processing and reduction annealing ${ }^{(4)}$, sputtering ${ }^{(5,6)}$, spray deposition ${ }^{(7)}$, laser ablation, ${ }^{(8,9)}$ and high energy ball milling ${ }^{(10-11)}$. Ball-milling produces extremely hard, micrometer size particles, made up of nanometer size grains. The grain size reduction into the nano size regime increases the hardness and the strength of the particles inversely with square root of the average grain size, according to the Hall-Petch equation ${ }^{(12)}$, but not necessarily with the same slope. The material is also highly work hardened by the ball milling process, thus adding to the particles' hardness.

Although mechanically-processed powders possess unique microstructures and compositions ${ }^{(12,13)}$ these powders must still be consolidated into a final shape for commercial application while retaining the nanocrystalline microstructure. Usually, consolidation involves two steps: cold compaction to bring the particles into intimate contact, followed by sintering at an elevated temperature to obtain bonding. As noted above, ball milled powder particles are extremely hard and resist most methods of cold consolidation. Therefore we employed a cold dynamic compaction method to 
produce high density, high hardness compacts from ball-milled powders. In this paper we present our results on cold compaction of ball milled iron blends and stainless steel 304 powders of nanometer grain size.

\section{EXPERIMENTAL}

Iron and iron nano-powders were mechanically processed in a commercial attritor with a tank capacity of $1 \mathrm{~kg}$, according to a procedure described in detail elsewhere ${ }^{(14)}$. Briefly, $500 \mathrm{~g}$ charges of powders with the desired composition as listed in table 1 were inserted into the mill. Grinding media were $6.35 \mathrm{~mm}$ diameter stainless steel balls, with a ball-to-powder ratio of approximately 20:1. The attritor speed was maintained at $300 \mathrm{rpm}$. Prior to processing, the attritor tank was flushed several times with nitrogen (or argon in several cases) to establish a clean reactive $(\mathrm{N})$ or non-reactive (Ar) atmosphere. During mechanical alloying, the environment was maintained by flushing approximately $2 \mathrm{~L}$ of gas (nitrogen or argon) per minute through the attritor tank. A positive pressure was kept inside the tank during the processing. The nitrogen and oxygen contents in the final powder products were measured using a gas fusion analyzer ${ }^{(14)}$ (table 1).

For comparison two different regular iron powders were processed by the same way as the nanocrystalline powders.

Three different cold compaction techniques were used:

\section{i) Cold Isostatic Pressing-CIP}

All powders were CIPed to $350 \mathrm{MPa}$ in rubber bags in an isostatic press. The pressure was increased to the maximum pressure in about 3 min held there for an additional $3 \mathrm{~min}$. Then the pressure was reduced rapidly (few seconds). 
Table 1) summary of ball milled processed powders and powder characteristics according to references 14 and 15.

\begin{tabular}{|c|c|c|c|c|c|c|c|}
\hline \multicolumn{2}{|l|}{ Sample } & \multirow{2}{*}{$\begin{array}{c}\text { Processing } \\
\text { time } \\
\text { [h] }\end{array}$} & \multicolumn{3}{|c|}{$\begin{array}{c}\text { Impurity content } \\
\text { [mass fraction } \%]\end{array}$} & \multirow{2}{*}{$\begin{array}{l}\text { Grain } \\
\text { size } \\
\text { [nm] }\end{array}$} & \multirow{2}{*}{$\begin{array}{c}\text { Particle } \\
\text { size } \\
\text { [nm] }\end{array}$} \\
\hline Description $^{(0, i, i, i)}$ & $\begin{array}{l}\text { Struc } \\
\text {-ture }\end{array}$ & & $\overline{\mathbf{N}}$ & 0 & $\bar{C}$ & & \\
\hline $\mathrm{Fe}[\mathrm{N}]$ & \multirow{6}{*}{ bcc } & 150 & 1.35 & 2.54 & & 5.3 & $\begin{array}{c}100 \mathrm{~nm} \\
3 \mu \mathrm{m}\end{array}$ \\
\hline $\mathrm{Fe}-\mathrm{N}[\mathrm{N}]$ & & 100 & 2.94 & 2.52 & & 3.3 & $\begin{array}{c}100 \mathrm{~nm} \\
3\end{array}$ \\
\hline $\mathrm{Fe}[\mathrm{Ar}]$ & & 150 & 0.16 & 1.41 & & 7.6 & $100 \mathrm{~nm}$ \\
\hline $\mathrm{Fe}-2 \mathrm{C}[\mathrm{N}]$ & & 150 & 0.50 & 6.07 & 1.72 & 4.5 & $100 \mathrm{~nm}$ \\
\hline $\mathrm{Fe} 2 \mathrm{Al}[\mathrm{N}]$ & & 150 & 0.93 & 4.39 & & 5.6 & $4 \mu \mathrm{m}$ \\
\hline $\mathrm{Fe} 2 \mathrm{Al}-2 \mathrm{C}[\mathrm{N}]$ & & 150 & 1.29 & 2.99 & 1.86 & 3.9 & $5 \mu \mathrm{m}$ \\
\hline 304 SS [N] & \multirow{3}{*}{ fcc } & 100 & 0.51 & 6.54 & & 3.8 & $0.2-1 \mathrm{~mm}$ \\
\hline $\mathrm{Fe}-18 \mathrm{Cr}-8 \mathrm{Ni}-\mathrm{N}[\mathrm{N}]^{*}$ & & 100 & 4.59 & 2.05 & & 4.1 & $\begin{array}{c}100 \mathrm{~nm} \\
5 \mu \mathrm{m}\end{array}$ \\
\hline $\mathrm{Fe}-18 \mathrm{Cr}-8 \mathrm{Ni}[\mathrm{N}]$ & & 100 & 0.84 & 1.05 & & 13.3 & $\begin{array}{c}100 \mathrm{~nm} \\
3 \mu \mathrm{m}\end{array}$ \\
\hline
\end{tabular}

${ }^{*}$ The 304 SS contained approximately $18 \mathrm{Cr}-8 \mathrm{Ni}$ including additional elements.

The main additive is Si.

**Measured by X-ray techniques according to References 14, 15, 16.

(i) Powders which were processed in a nitrogen or argon environment are indicated by [N] or [Ar] by their name.

(ii) In order to increase the nitrogen content in the powder, in several cases $\mathrm{Fe}$ and/or $\mathrm{Cr}$ nitrides were added to the original powders before ball milling.

For these cases the letter $\mathrm{N}$ was added to the powder name.

(iii) The numbers preceding the elemental names in column 1, table 1 represents their content in units of mass fraction percent.

\section{ii) Cold Die Pressing}

In order to check the effect of high pressure on the consolidation characteristics, Fe[N] nanocrystalline as well as regular Fe powders were cold pressed in a closed die up to $2.5 \mathrm{GPa}$. The die consisted of a carbide cylinder in a steel cylindrical sleeve and two carbide push rods. A compressive force 
was applied to the push rods by a standard screw-driven mechanical testing machine. The actual force on the powder was measured using a double load cell that subtracted the load applied to the cylinder. The change in the powder volume was determined from the displacement of the pushing rods.

\section{iii) Cold Dynamic Compaction - CDC}

A weight of $45 \mathrm{~kg}$ was dropped on a specimen from a height of about 4.5 $\mathrm{m}$ as illustrated in Figure 1. The specimen consisted of a $10 \mathrm{~mm}$ diameter and $12 \mathrm{~mm}$ to $15 \mathrm{~mm}$ long cylinder of CIPed powder. The cylinder was either partially confined by a thin stainless steel foil, totally confined by a copper tube (with open ends) of $10 \mathrm{~mm}$ diameter and $1 \mathrm{~mm}$ wall thickness, or unconfined. The specimen was then placed on the base plate and concentered with the hammer, and subjected to a drop weight impact.

After the drop weight hit the sample, it bounced, falling again on the anvil. If the sample stayed in the same place after the first hit, it would be broken into many small pieces, each piece containing many cracks. In the first experiments, we wrapped the CIPed powder with stainless steel foil held together with adhesive tape. On impact, the tape frequently stuck to the impact bar, and the sample was broken. In latter experiments, after replacement of the adhesive tape with a rubber band or when alternatively the CIPed powders were inserted in a copper tube, or the as-CIPed compact directly placed on the anvil, a single solid compact was obtained.

After consolidation the compacts were sectioned for metallographic, density, and microhardness measurements. Vickers microhardness was performed using a $300 \mathrm{~g}$ mass for $12 \mathrm{~s}$. We estimate that the accuracy of density determination from the specimen weight and volume was better than 
$300 \mathrm{~kg} / \mathrm{m}^{3}$.

The as-received powders as well as the fracture surfaces of the compacted specimens were characterized by scanning electron microscopy (JEOL 840A microscope) ) using a voltage of $10 \mathrm{kV}$ to $15 \mathrm{kV}$.

\section{X-ray measurements}

$\mathrm{X}$-ray diffraction was used to measure grain size. $\mathrm{Cu} \mathrm{K} \alpha$ radiation $(\lambda=0.154060 \mathrm{~nm})$ was used. In order to get precise results, slow runs were performed with the following conditions: dwell time $25 \mathrm{~s}$, step size $0.05^{\circ}$ and $2 \theta$ ranging between $30^{\circ}$ and $140^{\circ}$. The grain size and the strain inside the grains were calculated using the procedure of Klug and Alexander ${ }^{(17)}$ and Williamson-Hall ${ }^{(18)}$

\section{3) RESULTS}

\section{1) Microstructure and density of CIPed and cold die pressed ball milled powders}

Secondary electron images of metallographic cross-sections of $\mathrm{Fe}[\mathrm{N}]$ powders pressed in a cold die to different pressures are presented in Figure 2. Usually the microstructure of the powders consisted of two particle populations : one ranging between $50 \mathrm{~nm}$ to $200 \mathrm{~nm}$ and the other ranging between $1 \mu \mathrm{m}$ to $50 \mu \mathrm{m}$, with an average particle size of about $3 \mu \mathrm{m}$ to $5 \mu \mathrm{m}$. The larger particles are actually an agglomeration of smaller ones, $50 \mathrm{~nm}$ to $100 \mathrm{~nm}$ in diameter, cold welded together. The larger particles are much smoother than the smaller ones. In contrast, the Fe-2Al-2C [N] powder contains a larger average particle size of about $2 \mu \mathrm{m}$ to $6 \mu \mathrm{m}$. Particles smaller than $0.1 \mu \mathrm{m}$ 
are rarely seen. Another exception was the $304 \mathrm{SS}$ [N] powder which consisted relatively large particles $(10 \mu \mathrm{m}$ to $500 \mu \mathrm{m})$ covered with the very small particle in the order of 50 to $100 \mathrm{~nm}$. The particles size of the different powders are also summarized in table 1.

As seen in Figure 2, upon pressing the $\mathrm{Fe}[\mathrm{N}]$ powder the average center-to-center distance between the particles and the porosity decrease with increasing die pressure. However, even at $2.5 \mathrm{GPa}$, significant porosity could still be observed. The density as a function of the die pressure is given in Figure 3. At the first stages of pressing there is a rapid increase in density from about $3000 \mathrm{~kg} / \mathrm{m}^{3}$ of the as received powder to about $4300 \mathrm{~kg} / \mathrm{m}^{3}$ at 0.12 $\mathrm{GPa}$. Then, there is a gradual slowing in densification up to $1 \mathrm{GPa}(5200$ $\mathrm{kg} / \mathrm{m}^{3}$ ). A further increase of pressure to $2.5 \mathrm{GPa}$ caused the density to increase to $5900 \mathrm{~kg} / \mathrm{m}^{3}$. Pores could also be observed inside the large particles of Figure $2 b$.

In contrast, the density change with pressure of the regular Fe powder has a different character, as shown in Figure 3 . Up to $0.15 \mathrm{GPa}$ a rapid density increase occurs from $2400 \mathrm{~kg} / \mathrm{m}^{3}$ of the as received powder to 5700 $\mathrm{kg} / \mathrm{m}^{3}$. The density increase saturated at about $7700 \mathrm{~kg} / \mathrm{m}^{3}$ for a pressure of about $1.5 \mathrm{GPa}$, which is much larger value than was obtained for the NM powder.

\section{2) Cold Dynamic Compaction Specimens}

After compaction the density and hardness were non-uniform' as illustrated in Figure 4. The maximum hardness and density were obtained at the sample center. As a result of impact, the anvil was deformed and one side of the sample acquired the semi-hemispherical contour of the anvil. 
The hardness and density measurements were made on the central part of the samples.

\section{3) Hardness and Density measurements CIPed and CDC samples}

The hardness and density results from different consolidation techniques are summarized in tables 2 and 3 . The hardness of the matrix composed of the smaller particle, and the hardness of the larger particles ftarger than 30 $\mu \mathrm{m})$ regularly found embedded inside the are shown in table 2 . The density of the as CIPed and CDC samples processed in three different sample forms (see details in the experimental section) are given in Table 3.

Table 2) Vickers hardness of consolidated ball milled powder for different consolidation paths. There was an uncertainty of less then $10 \%$ in the results.

\begin{tabular}{|c|c|c|c|}
\hline Powder type & \multicolumn{2}{|c|}{ CIPed } & \multirow{2}{*}{ CDC } \\
\cline { 2 - 3 } & $\begin{array}{c}\text { matrix } \\
{\left[H_{\mathrm{V}}\right]}\end{array}$ & $\begin{array}{c}\text { particle } \\
{\left[\mathrm{H}_{\mathrm{V}}\right]}\end{array}$ & \begin{tabular}{c}
$\left.\mathrm{H}_{\mathrm{V}}\right]$ \\
\hline
\end{tabular} \\
\hline
\end{tabular}

bcc Fe nano-grained powders

\begin{tabular}{|l|c|c|c|}
\hline Fe [N] & 120 & 1200 & 1300 \\
\hline $\mathrm{Fe}(\mathrm{Ar})$ & 110 & 1100 & 1400 \\
\hline $\mathrm{Fe}-2 \mathrm{Al}-2 \mathrm{C}[\mathrm{N}]$ & 120 & 1330 & 1310 \\
\hline $\mathrm{Fe}-2 \mathrm{Al}[\mathrm{N}]$ & 120 & 530 & 1500 \\
\hline $\mathrm{Fe}-2 \mathrm{C}[\mathrm{N}]$ & 110 & 630 & 1500 \\
\hline $\mathrm{Fe}-\mathrm{N}[\mathrm{N}]$ & 130 & 500 & 1250 \\
\hline
\end{tabular}

fcc Fe nano-grained powders

\begin{tabular}{|l|c|c|c|}
\hline 304 SS [N] & 120 & 900 & 890 \\
\hline Fe18Cr8Ni-N [N] & 130 & 750 & 1150 \\
\hline Fe-18Cr-8Ni [N] & -130 & 990 & 1090 \\
\hline
\end{tabular}

* The 304-N-SS [N] powder contain huge particles with diameters of up to 7 $\mathrm{mm}$. The hardness of these particles ranged between $500 \mathrm{H}_{V}$ to $1070 \mathrm{H}_{\mathrm{V}}$. 
Table 3) Density measurements of consolidated ball milled powder for different consolidation routes. We estimate that the accuracy of density determination was better than $300 \mathrm{~kg} / \mathrm{m}^{3}$.

\begin{tabular}{|c|c|c|c|c|}
\hline \multirow[t]{2}{*}{ Powder type } & \multirow{2}{*}{$\begin{array}{l}\text { CIPed } \\
{\left[\mathrm{kg} / \mathrm{m}^{3}\right]}\end{array}$} & \multicolumn{3}{|c|}{ Cold Dynamic Consolidation } \\
\hline & & $\begin{array}{c}\text { as CIPed } \\
{\left[\mathrm{kg} / \mathrm{m}^{3}\right]}\end{array}$ & $\begin{array}{l}\text { thin foil } \\
{\left[\mathrm{kg} / \mathrm{m}^{3}\right]}\end{array}$ & $\begin{array}{l}\text { Cu tube } \\
{\left[\mathrm{kg} / \mathrm{m}^{3}\right]}\end{array}$ \\
\hline
\end{tabular}

bcc Fe nano-grained powders

\begin{tabular}{|l|l|l|l|l|}
\hline $\mathrm{Fe}[\mathrm{N}]$ & 4600 & 6250 & 6900 & \\
\hline $\mathrm{Fe}(\mathrm{Ar})$ & 4600 & 6300 & 7300 & 7300 \\
\hline $\mathrm{Fe}-\mathrm{N}[\mathrm{N}]$ & 4500 & 6250 & & 7300 \\
\hline $\mathrm{Fe}-2 \mathrm{Al}-2 \mathrm{C}[\mathrm{N}]$ & 4800 & 6300 & 7300 & \\
\hline $\mathrm{Fe}-2 \mathrm{Al}[\mathrm{N}]$ & 4800 & 6350 & & \\
\hline $\mathrm{Fe}-2 \mathrm{C}[\mathrm{N}]$ & 4800 & 6400 & 7300 & \\
\hline
\end{tabular}

fcc Fe nano-grained powders

\begin{tabular}{|l|l|l|l|l|}
\hline 304 SS [N] & 5400 & 6200 & & \\
\hline Fe18Cr8Ni-N [N] & 4300 & 6100 & & \\
\hline Fe-18Cr-8Ni [N] & 4300 & 6250 & & \\
\hline
\end{tabular}

\section{4) Grain size of CDC specimens}

X-ray'diffraction data for the grain size and stress measurements of four typical cold dynamic compacted samples are compared to those of the asreceived powder in table 4 . The grain size of the CDC-specimens are of the same order of magnitude as the as received powders, within the uncertainty of the measurement. It should be mentioned that the grain size of the CDC Fe [Ar] was smaller by a factor of 3 compared to the as received grain size. It is possible that the work hardening in this specimen is larger. This subject is now under investigation. 
Table 4: Grain size and strain of cold dynamic-compacted samples compared to the as received powder measured from 3 different peaks.

\begin{tabular}{|c|c|c|}
\hline \multirow{2}{*}{ Sample } & \multicolumn{2}{|c|}{ GRAIN-SIZE } \\
\cline { 2 - 3 } & $\begin{array}{c}\text { Initial } \\
\text { Powder } \\
\text { [nm] }\end{array}$ & $\begin{array}{c}\text { After CDC } \\
\text { [nm] }\end{array}$ \\
\hline Fe [Ar] & $13.7 \pm 1.0$ & $4.7 \pm 1.0$ \\
\hline Fe-2Al [N] & $7.4 \pm 1.0$ & $6.0 \pm 1.0$ \\
\hline F-2Al-2C [N] & $5.2 \pm 1.0$ & $4.5 \pm 1.0$ \\
\hline Fe-2C[N] & $6.0 \pm 1.0$ & $7.3 \pm 1.0$ \\
\hline
\end{tabular}

\section{4) Fracture Morphology of CIPed and Cold Dynamic Compaction Samples}

Samples were broken by hand (or hammer, if necessary) to reveal the internal pore morphology as viewed on the resulting fracture surfaces. Secondary electron images of as-received internal morphology, CIPed, and cold dynamic compaction fracture morphology of regular powders and of ball milled powders are presented in Figures 5 to 7 . The as-received regutar $\mathrm{Fe}$ powder, with $6 \mu \mathrm{m}$ particle size, is illustrated in Figures $5 \mathrm{a}$ and $5 \mathrm{~b}$ at two magnifications. As seen in the figures, the particles make contact at only few isolated locations creating large pores between the particles. Therefore, the tap density is low $\left(2400 \mathrm{~kg} / \mathrm{m}^{3}\right)$. CIPing the powder caused some deformation of the particles at the contact points, as shown in Figures $5 c$ and $5 d$. However, even after CIPing, there are still many pores between the particles. In contrast, the dynamic mechanical compaction closed most of the pores, as illustrated in Figures $5 \mathrm{e}$ and $5 \mathrm{f}$. Moreover, the particles were highly deformed, 
losing their spherical shape. In some cases, compacts were obtained in which individual particles could not be resolved whatsoever.

A comparison between the as-received, the as CIPed, and the cold dynamic compacted fracture morphology of $\mathrm{Fe}-2 \mathrm{C}[\mathrm{N}]$, and $\mathrm{Fe}-2 \mathrm{Al}[\mathrm{N}]$ powders are given in Figures 6 and 7, respectively. The as-received powder morphology are given in (a) and (b) in Figures 6 and 7. Large pores between the particles may be observed. The CIPing caused some shrinking of the pores, but large pores still exist, as seen in (c) and (d) in Figures 6 and 7. The original powder particle morphology was preserved and the compact was friable by manual pressure. In contrast, CDC caused consolidation and intimate contact between the powder particles, as illustrated in $(e)$ and $(f)$ of the Figures 6 and 7 . The pores were almost completely closed. Similar behavior wàs observed for all CDC samples.

It should be noted that after CDC the samples were extremely hard and brittle. The brittleness was due to lack of bonding and highly strained material.

\section{4) DISCUSSION}

In mechanical processing of iron powders in an attrition ball-mill the powder particles are subjected to a series of high-energy impacts. The particles are initially plastically deformed and cold worked. Continued mechanical processing results in repeated fragmentation and subsequent cold-welding leading eventually to micrometer size particles with equiaxed nanocrystalline microstructures ${ }^{(13)}$. After approximately 100 hours of mechanical processing, the particles are roughly spherical, with a uniform nanocrystalline microstructure. The powder is mainly composed of particles with diameters ranging from $50 \mathrm{~nm}$ to $10 \mu \mathrm{m}$. 
Occasionally, particles as large as $50 \mu \mathrm{m}$ were observed. Several fcc $\mathrm{Fe}$ powders contained larger particles of up to $1 \mathrm{~mm}$ in diameter-see also table 1 . During cold welding by the milling, many pores are also incorporated into the particles, as seen in Figures $2 a$ and $2 b$. The presence of such pores and the irregularity of particle size might have an influence on the hardness of these particles and on the final density, as will be discussed later.

These large particles were found to have interesting and, at first, unexpected characteristics. Because these particles were thought to be indicative of what might be achieved in bulk, and as such motivated much of the research that followed, a brief discussion of what was found out about these large particles is worthwhile.

Since hardness is related inversely to the square root of the grain size ${ }^{(18)}$, the powder particles should be very hard. The cold worked condition of the particles also contributes to the hardness. This is verified by the microhardness measurements (table 2). The $50 \mu \mathrm{m}$ particles' high hardness and microprobe microanalysis indicate that they are formed during the ball milling and are not the original Fe powder. Indeed, the process of powder creation by ball milling is similar to the cold dynamic compaction. In the former process, the balls collide with very high energy while the powder is in between, somewhat similar to the CDC process. Indeed, the CDC-compacted bodies reached hardness of $1300 \mathrm{H}_{V}$ to $1400 \mathrm{H}_{V}$, while the large particles found in the as received powders were $1100 \mathrm{H}_{V}$ to $1300 \mathrm{H}_{V}$. The hardness of CDC-compacted bodies is even higher than compacted bodies processed by a pulse pressure of $15 \mathrm{GPa}$ via explosive bonding which reached a maximum of $1000 \mathrm{H}_{v}{ }^{(12)}$. . 
Still, there are large variations in the microhardness of the $50 \mu \mathrm{m}$ particles ranging between $500 \mathrm{H}_{\mathrm{V}}$ and $1200 \mathrm{H}_{\mathrm{V}}$ as compared to $100 \mathrm{H}_{\mathrm{V}}$ for the bulk microhardness of the CIPed powders. The hardness of the particles depends on several factors as follows:

\section{1) Grain size}

The hardness and strength of the particles is inversely proportional to the square root of the average grain size, similar to the Hall-Petch relation ${ }^{-(18)}$.

\section{2) Particle size}

In order to obtain a significant microhardness reading, the particle size has to be at least 4 to 6 times larger than the indentation, otherwise it will be influenced by the matrix (the media surrounding the big particles i. e: the smaller particles) on the reading. Since the matrix is usually soft, one obtains lower hardness values for smaller particles.

\section{3) Number and size of voids incorporated inside the welded particles}

As mentioned above, the particles contain pores and voids incorporated during the ball-milling process (see void incorporated inside the particles in Figures $2 \mathrm{a}$ and $2 \mathrm{~b})$. Naturally, if the microhardness was taken in a place where a void exists, the reading will be lower. This may be the reason that the microhardness of the largest particles in the 304- SS [N] powders were lower than those of the other large particles and the large scattering in the hardness results.

\section{4) Hardness of the matrix surrounding the particles}

If the matrix surrounding the particle is soft, the large particle might sink in the matrix and the measured hardness reading will represent the matrix rather than the particle. In places where the microhardness measurements were 
made for large particles embedded in the dark matrix, which contained larger porosity, the large particles fractured during the measurements.

\section{Effect of particle size and morphology on compacting ball milled powders}

Usually, there are two stages in the creation of a solid body from powders: (i) bringing the particles into intimate contact, and (ii) densification by pore closing. While densification mechanisms relying on diffusion may be greatly accelerated at relatively low temperatures by fine grain size, it is necessary to achieve some initial compaction with finely dispersed porosity before these mechanisms become effective. This is usually accomplished by pressing the fine powder to cause particle rearrangement and plastic compaction. The fineness of the powder particles determines how fine the porosity will be after pressing. It was reported that the particle size plays a central role in the densification process $^{(19)}$. For example; The consolidation characteristics of two Fe powders with approximately the same grain size but three order of magnitude difference in particle size are completely different. For nano-grains in nano-particte powder the particle size is so small that particle rearrangement caused by CIPing is sufficient to make densification by curvature-driven diffusion effective for eliminating the resulting fine porosity during sintering. If however, heat and pressure are applied (i.e., HIP), further (but minor) densification occurs compared to CIPing and sintering. In contrast, the CIPing followed by sintering of ball milled nanograins in micro-particles ciid not changed the hardness of the CIPed body while HIPing was required to increase the density and hardness significantly. This behavior was attributed to the fact that the nanograin particles are extremely hard as well as severe cold worked of the powder. Before diffusion can be effective, it is 
necessary to bring the particles into intimate contact with a fine porosity and their hardness eliminates plasticity as a means of accomplishing this. Onty-HIPing of the powder allows densification to proceed because the material becomes softer at elevated temperatures.

The results here show that the existence of very large partictes, as is the case in 304-SS [N] (average particle size of $500 \mu \mathrm{m}$ make plastic flow difficult. Much higher pressure (or temperature during HIP) is then needed to obtain the same density as for powders without such larger particles. For instance, in order to HIP the $\mathrm{Fe}[\mathrm{N}]$ (average particle size of $5 \mu \mathrm{m}$ ) and get a the maximum density one has to raise the temperature (at pressure of $200 \mathrm{MPa}$ ) to about $580^{\circ} \mathrm{C}$ (This will be published separately in detail ${ }^{(20)}$ ). On the other hand, the HIPing temperature of powder with a larger particte size has to be above 850 ${ }^{\circ} \mathrm{C}$ in order to get the same effect. A similar case was observed during the CDC. The 304-SS [N] had much lower hardness $\left(890 \mathrm{HV}_{\mathrm{V}}\right)$ as compared to more than $1100 \mathrm{HV}_{\mathrm{V}}$ in CDC compacts from Fe-18Cr-8 $\mathrm{Ni}[\mathrm{N}]$ and $\mathrm{Fe}-18 \mathrm{Cr}-8$ $\mathrm{Ni}-\mathrm{N}$ [N] which have average particle sizes of 2 up to $4 \mu \mathrm{m}$.

\section{5) CONCLUSIONS}

A variety of iron and iron alloys (stainless steel) powders containing nanograined particles were prepared by ball milling. The high hardness of the ball milled particles is due to the small grain size and highly work hardening condition and requires high pressure during cold compaction to obtain intimate contact between the particles. CIPed compacts to $0.35 \mathrm{GPa}$ had a low density (approximately $60 \%$ of theoretical), low hardness $\left(100 \mathrm{H}_{\mathrm{v}}\right.$ ), and low fraction of contact between the surfaces of the particles. Increase in the compaction 
pressure to $2.5 \mathrm{GPa}$ caused an increase in the density to about $72 \%$, but did not succeeded to improve the intimate contact between the particle surfaces.

A cold dynamic compaction method found to produce high density, high hardness compacts. In this method CIPed powder compacts are placed on the anvil of a drop weight impact tester and subjected to drop weight impact. The resulting compacts had densities approaching $95 \%$ of the theoretical maximal values. The hardness was in excess of $1400 \mathrm{H}_{\mathrm{V}}$, and the particles were in intimate contact, with greatly reduced porosity. No grain growth was observed during the dynamic process.

The dynamically compacted bodies were extremely hard yet brittle. It is expected that a heat treatment must be performed to improve bonding between the deformed particles to increase the ductility. Finding the proper heat treatment to get reasonable ductility white maintaining the relatively smatl grain size is now under investigation.

\section{REFERENCES}

1) J. Weissmuller, "Nanocrystalline Material=An Overview" Synthesis and processing of Nanocrystalline powders" - $\mathrm{D}$. L. Bourell Ed., Pro. TMS Annual Meeting, Anaheim California, 4-8 Feb. 1996.

2) $\mathrm{H}$. Gleiter, in Deformation of Polycrystals: Mechanisms and Microstructures, N. Hansen, A. Horsewell, and T. Leffers, Eds. Riso National Laboratory, Roskilde, 1981, pp. 15-21.

3) H. Gleiter. Prog. Mater. Sci. Vol. 33 (1989) pp. 223-315.

4) C. Persad, S. Raghunathan, A. Manthiram, M. Schmerling, D. L.. Bourell, Z. Eliezer, and H. L. Marcus: in Solid State Powder Processing, A. H.

Clauer and J. J. Barbadillo, Eds. TMS Warrendale, PA, 1990, pp -357-364.

5) R. S. Averback, H. Hahn, H. J. Hofler, and J. C. Logas: Appl. Phys. Lett., Vol. 57 (1990) pp. 1745-1747.

6) H. Trapp: Diploma Thesis, Universitat des Saarlandes Saarbrucken, 1990.

7) E. Hellstern, H. J. Fecht, Z. Fu, and́ W. L. Johonson. J. Appl. Phys., Vol. 65 (1989) pp. 303-310. 
8) M. D. Morse: Chem. Rev. Vol. 86 (1986) pp. 1049-1109.

9) K. Lai Hing, P. Y. Cheng, and M. A. Duncam. J. Phys. Chem. Vol-94(1987) pp. 6521-6525.

10) J. S. C. Jang and C. C. Koch: Scripta Metall. Mater., Vol. 24 (4990) pp. 1599-1604.

11) C. C. Kjoch, Annu. Rev. Mater. Vol. 19 (1989) p. 121.

12) C. P. Dogan, J. C. Rawers, R. D. Govier, and G. Korth, NamoStructured Materials, Vol. 4 (1994) pp. 631 to 644.

13) J. C. Rawers, and R. C. Doan, Met. Trans. A Vol. 25A, (1994) p. 381.

14) J. C. Rawers C. P. Dogan, G. Slavens, R. D. Govier, and J. Siple: J. Mater. Synth. Proc. Vol. 1 (1993) p. 75.

15) J. C. Rawers, and G. Korth, "Microstructure of Attrition Ball-Milled and Explosively compacted Iron Powder", Nanostructured Materials Vol. 7 (1996) pp. 25-45.

16) H. P. Klug and L. E, Alexander, X-ray Diffraction Procedures for Polycrystalline and Amorphous Materials, $2^{\text {nd }}$ Ed, Wiley, New York, 1974.

17) G. K, Williamson and W. H. Hall, Acta Met. Vol. 1 (1953) pp. 22-31.

18) G. E. Fougere, J. R. Weertman, R. W. Siegel, and S. Kim, Scripta Met et Mater. Vol. 26, (1992), pp. 1879-1883.

19) Z. Livne, A. Munitz, J. C. Rawers, and R. J. Fields. Unpublished work 20) A. Munitz, Z. Livne, J. C. Rawers and R. J. Fields. Unpublished work 


\section{FIGURE CAPTIONS}

Figure 1) Schematic illustration of the drop tower experiment.

Figure 2) Secondary electron images of-cross-sections of die pressed $\mathrm{Fe}[\mathrm{N}]$ samples at different pressures. a) $0.35 \mathrm{GPa}$. b) $1.5 \mathrm{GPa}$. c) $2.5 \mathrm{GPa}$.

Figure 3) Density versus cold die pressure for two types of powders.

Figure 4) Schematic illustration of the cold dynamic compaction sample.

Figure 5) Secondary electron images demonstrating particle morphology of a regular. Fe powder ( $6 \mu \mathrm{m}$. particles) in three different cases: a-b)-As processed. c-d) Fracture surface of as CIPed compact. e-f) Fracture surface of CDC specimens.

Figure 6) Secondary electron images illustrating-particle morphology of a Fe-2c ball-milled powder in three -different cases: a-bj As processed. c-d) Fracture surface of as CIPed compact. e-f) Fracture surface of CDC specimens.

Figure 7) Secondary electron images illustrating particle morphology of a Fe-2Al ball-milled powder in three different cases: a-b) As processed. c-d) Fracture surface of as CIPed compact. e-f) Fracture surface of CDC specimens. 




Figure 1) Schematic illustration of the drop tower experiment. 

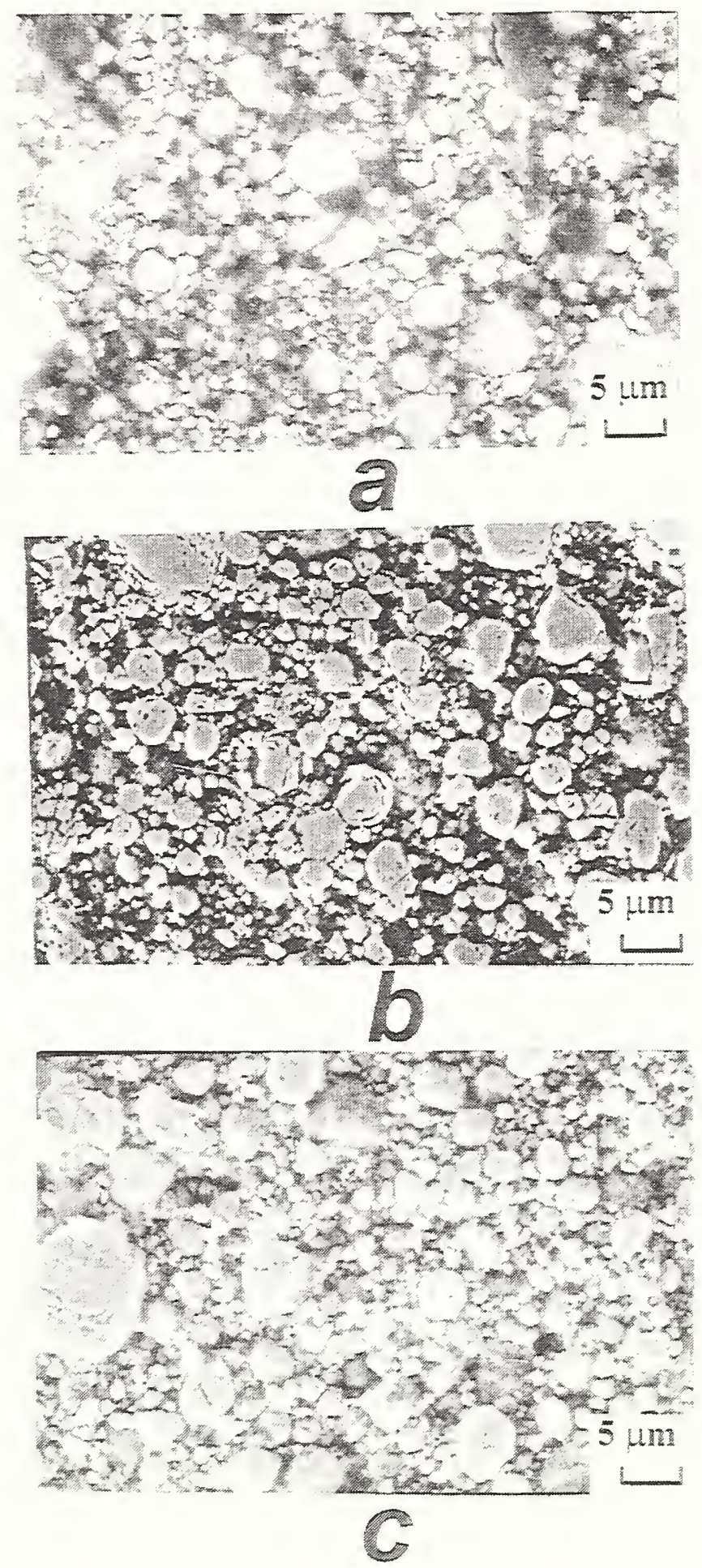

Figure 2) Secondary electron images of cross-sections of die pressed Fe [N] samples at different pressures. a) $0.35 \mathrm{GPa}$. b) $1.5 \mathrm{GPa}$. c) $2.5 \mathrm{GPa}$. 


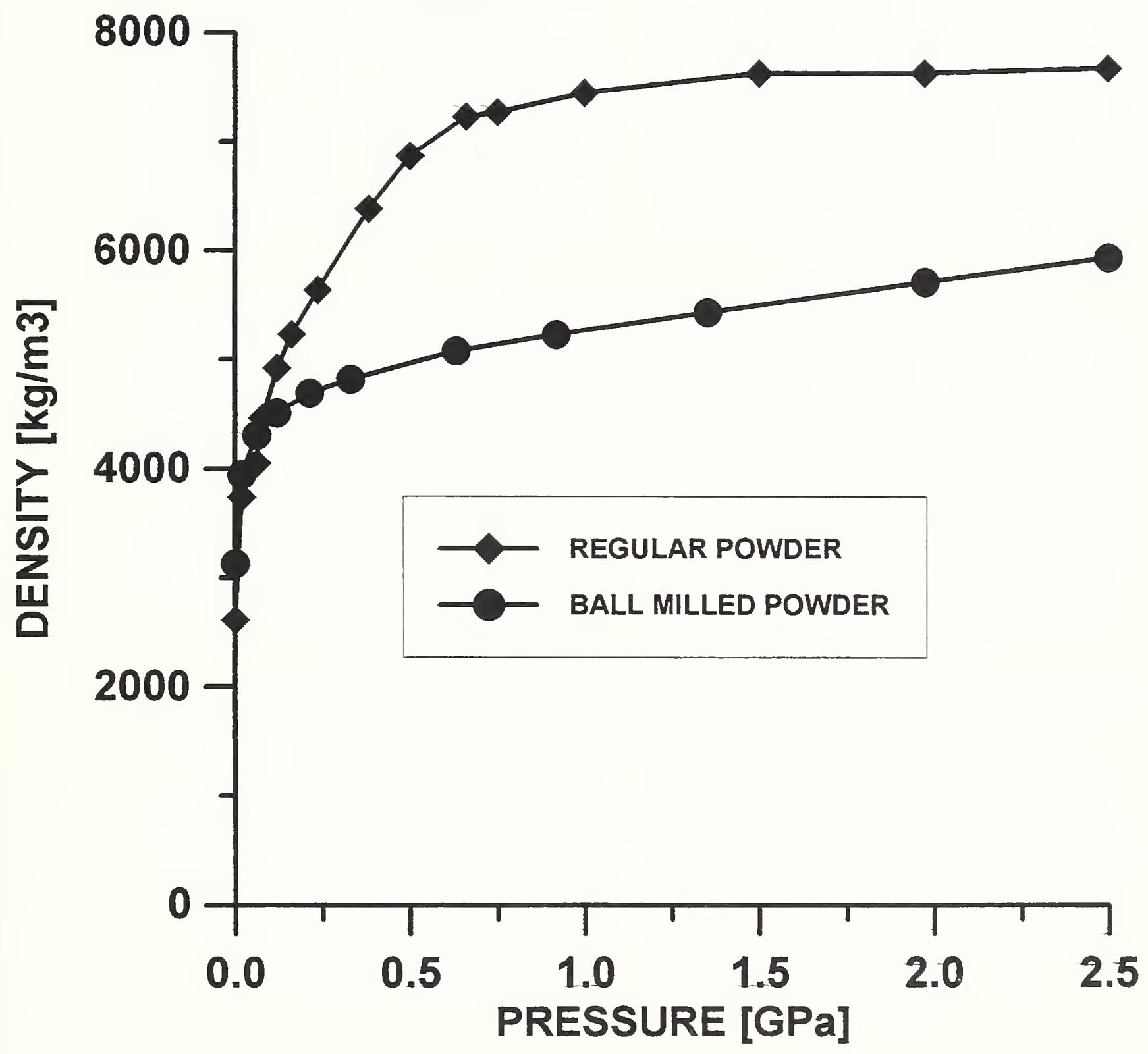

Figure 3) Density versus cold die pressure for two types of powders. 


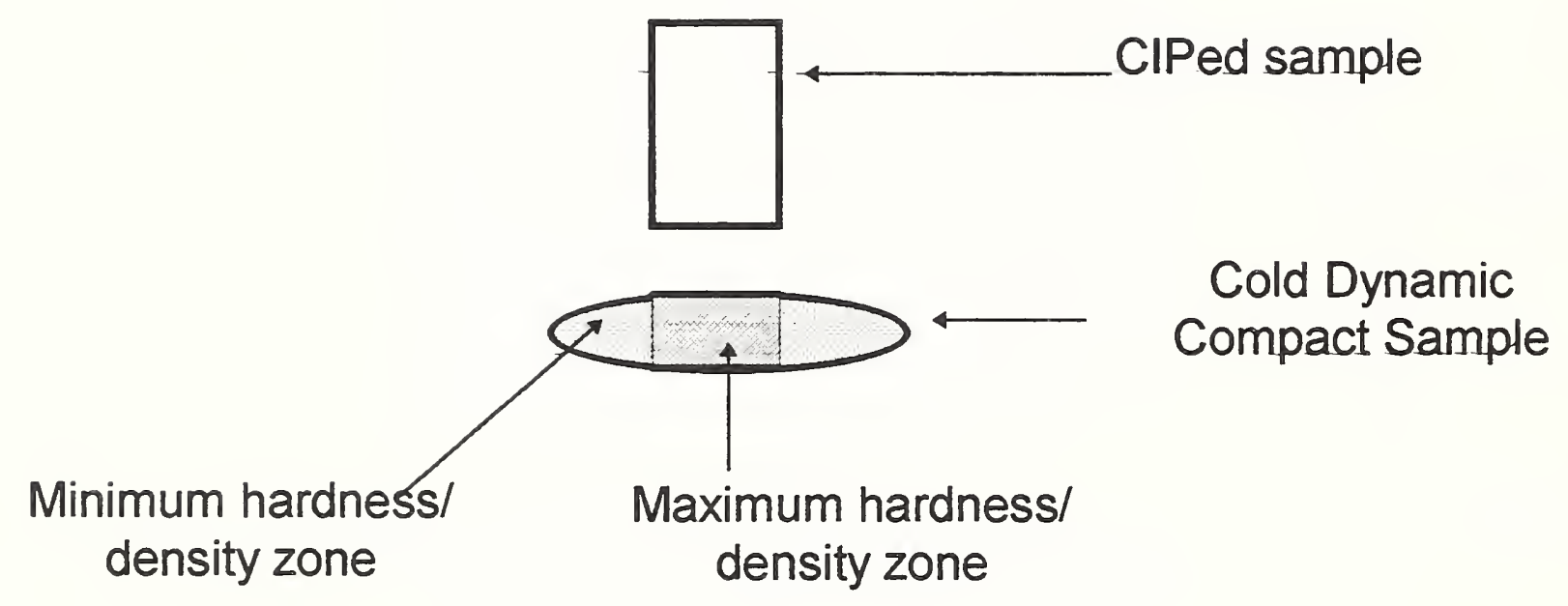

Figure 4) Schematic illustration of the cold dynamic compaction sample. 

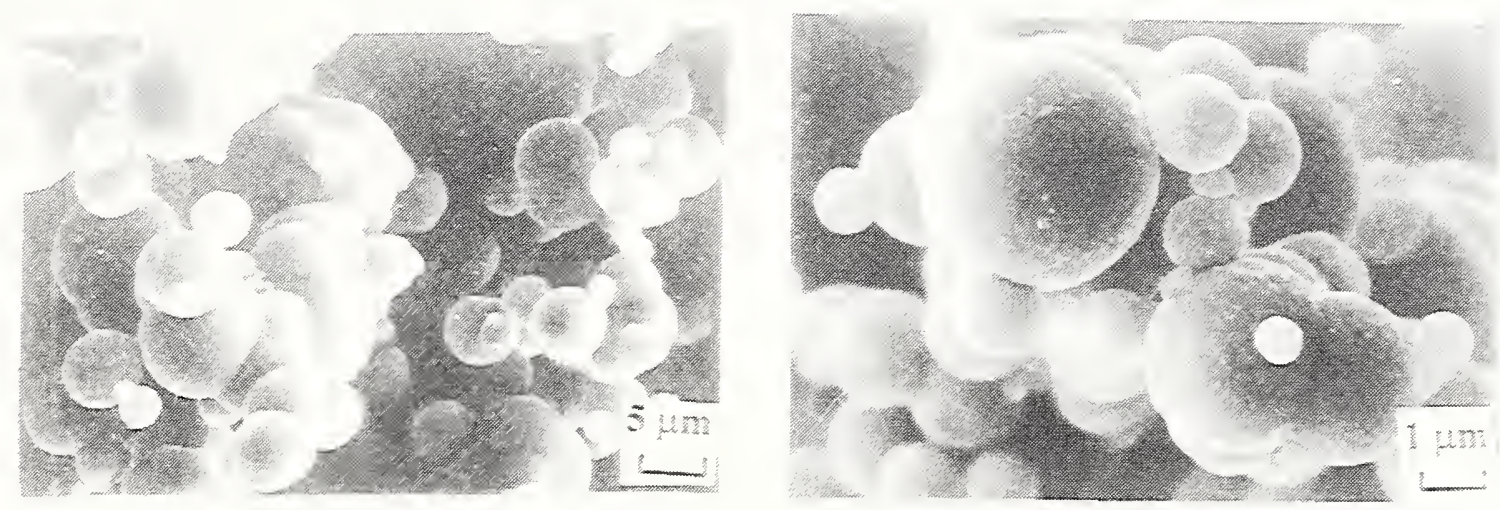

a
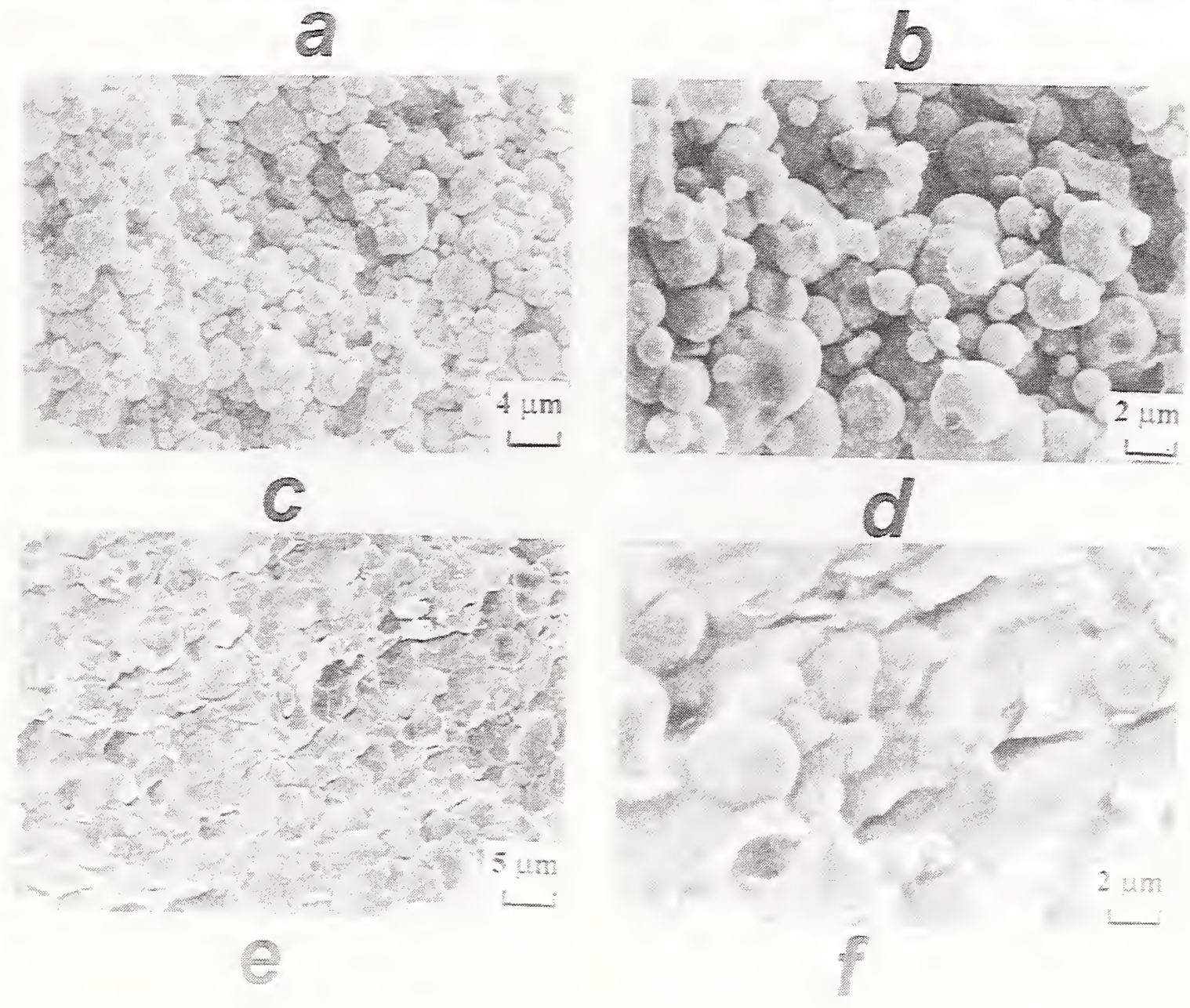

Figure 5) Secondary electron images demonstrating particle morphology of a regular $\mathrm{Fe}$ powder ( $6 \mu \mathrm{m}$ particles) in three different cases: a-b) As processed. $c$-d) Fracture surface of as CIPed compact. e-f) Fracture surface of CDC specimens. 


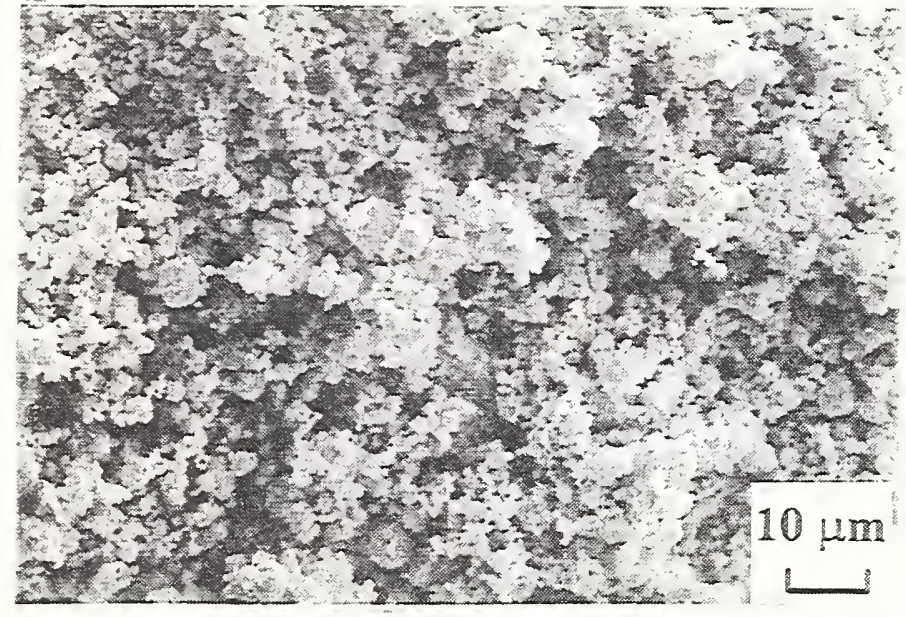

\section{a}
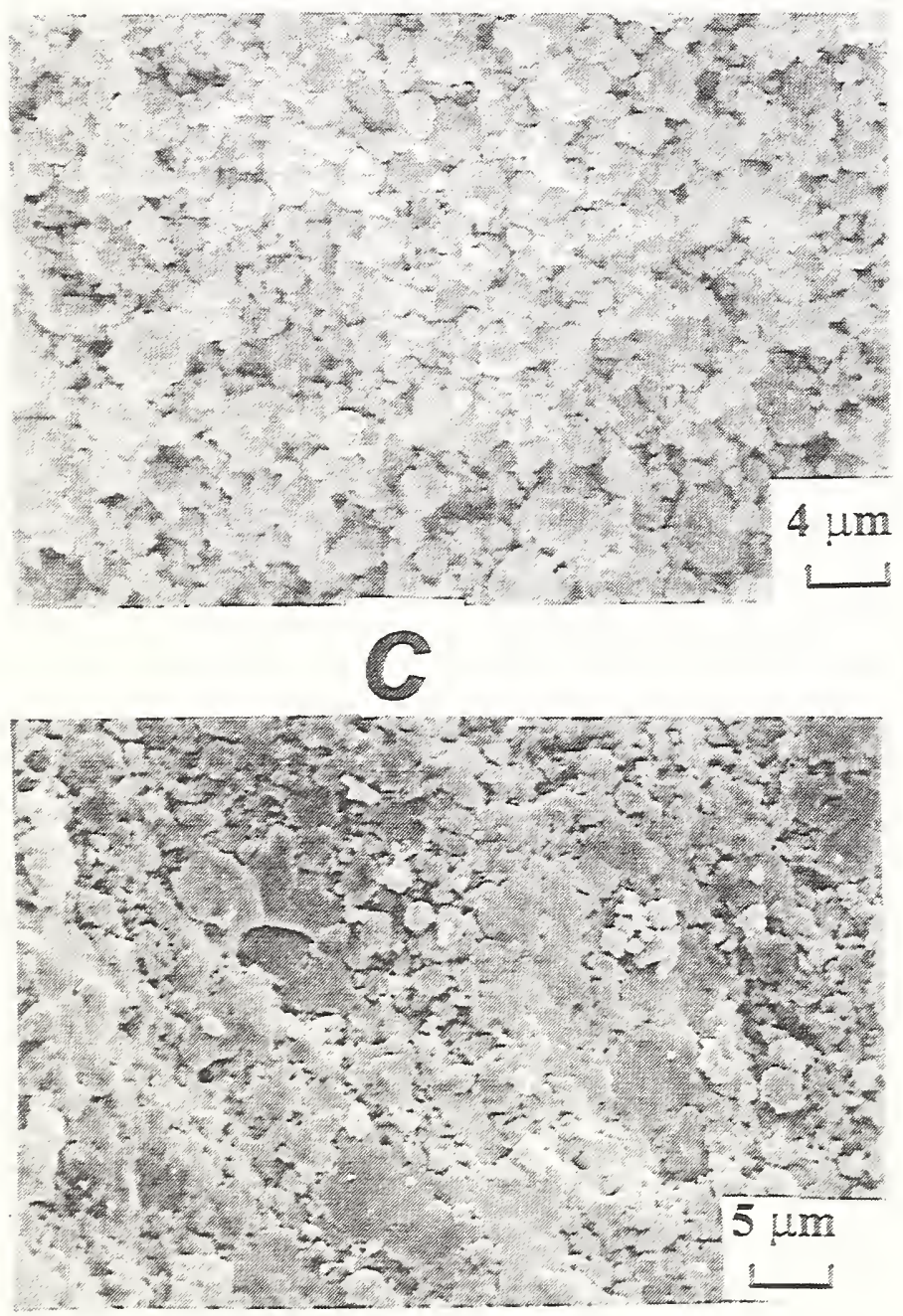

e


Figure 6) Secondary electron images illustrating particle morphology of a Fe-2c ball-milled powder in three different cases: $a-b)$ As processed. c-d) Fracture surface of as CIPed compact. e-f) Fracture surface of CDC specimens. 


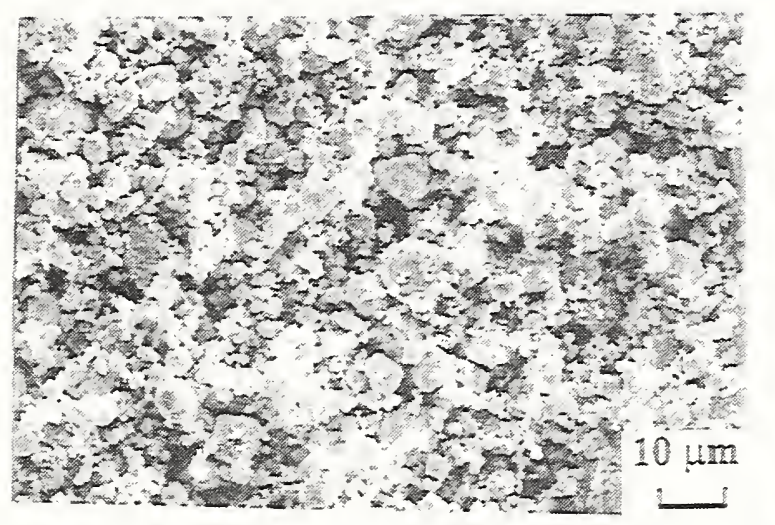

a

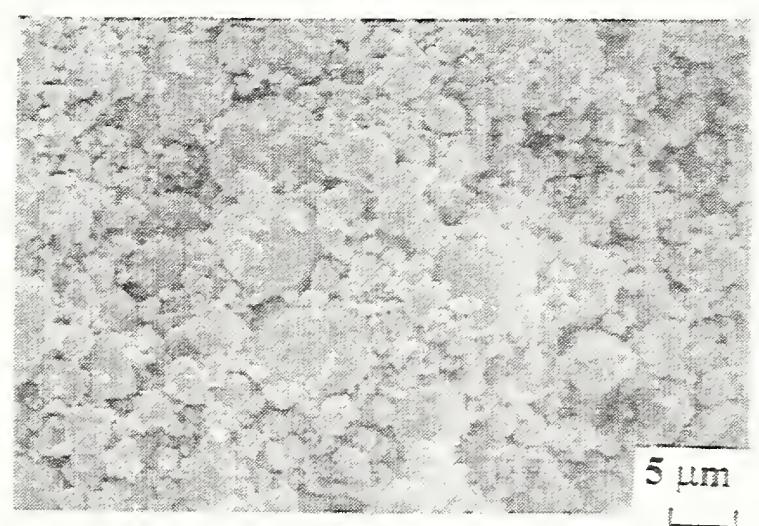

C



e

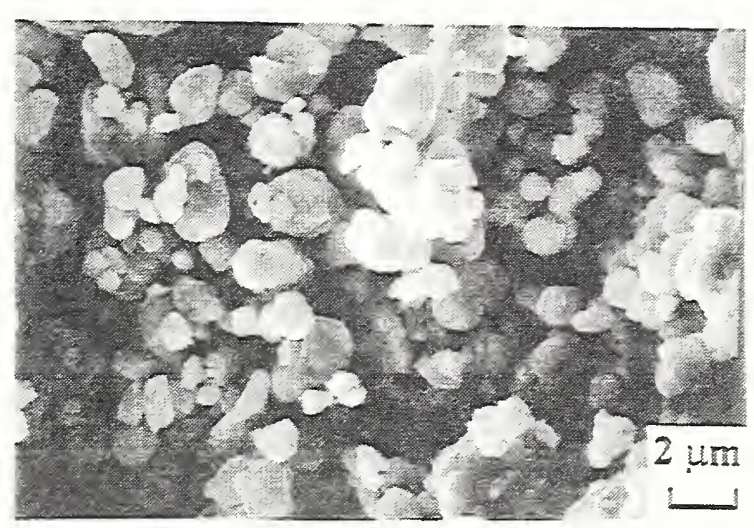

b



d

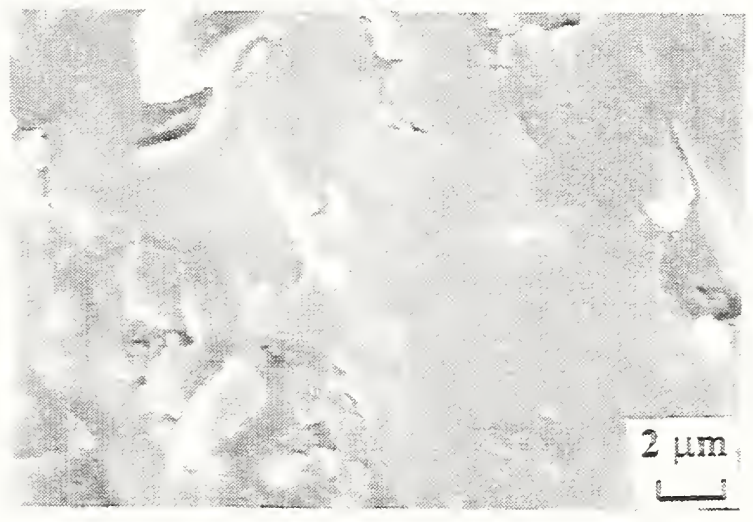

$=$

Figure 7) Secondary electron images illustrating particle morphology of a Fe-2Al ball-milled powder in three different cases: a-b) As processed. c-d) Fracture surface of as CIPed compact. e-f) Fracture surface of CDC specimens. 


